\title{
As serpentes de Virgílio e de Odorico Mendes: efeitos poéticos e autotextualidade em Geórgicas, 3.414-439 e em dois passos do canto 2 da Eneida $^{1}$
}

\section{The Snakes of Vergil and Odorico Mendes: \\ Poetic Effects and Self-Intertextuality in Georgics 3.414-439 \\ and in Two Passages from the Book 2 of the Aeneid}

\author{
Robson Tadeu Cesila \\ Universidade de São Paulo (USP), São Paulo, São Paulo / Brasil \\ robson.cesila@yahoo.com.br
}

Resumo: Neste artigo, examinaremos a passagem 3.414-439 das Geórgicas, em que Virgílio adverte sobre os perigos representados pelos ofídios venenosos ao gado, e buscaremos demonstrar, a partir desse belo trecho, um traço marcante do estilo virgiliano: a criação de efeitos poéticos de som, sintaxe e ritmo. Também analisaremos as relações autotextuais que se estabelecem entre alguns desses versos e duas famosas passagens da Eneida: o episódio da morte do sacerdote Laocoonte e de seus filhos por duas serpentes saídas do mar (En., 2.199-227) e o início do trecho que narra a execução do rei Príamo por Pirro (En., 2.469-475). Concomitantemente, refletiremos sobre como todos esses aspectos foram contemplados na versão poética de um dos maiores tradutores de Virgílio para o nosso idioma, Manuel Odorico Mendes (1799-1864).

Palavras-chave: Virgílio; Geórgicas 3; Eneida 2; Odorico Mendes; serpentes; autotextualidade.

Abstract: In this article we will discuss the passage 3.414-439 from the Georgics, in which Vergil warns of the dangers posed by poisonous snakes to the cattle. We will use this passage to try to demonstrate a striking feature of Vergil's style: the production of poetic effects of sound, syntax and rhythm. We will also analyse the self-intertextual

\footnotetext{
${ }^{1}$ Este artigo se origina de conferência que proferimos na "I Jornada do Grupo Odorico Mendes: as Geórgicas de Virgílio em tradução poética", evento que organizamos na Universidade de São Paulo (USP) em junho de 2019.
} 
relations that are established between some of these verses and two famous passages of the Aeneid: the episode of the death of Laocoon and his sons by two giant sea-snakes (Aen. 2.199-227) and the passage that recounts the murder of King Priam by Pyrrhus (Aen. 2.469-475). At the same time, we will reflect on how all these aspects were contemplated in the poetic Portuguese version by Manuel Odorico Mendes, one of the greatest translators of Vergil into Portuguese.

Keywords: Vergil; Georgics 3; Aeneid 2; Odorico Mendes; snakes; self-intertextuality.

No canto 3 das Geórgicas, que Virgílio consagra à atividade pecuária, é digno de destaque, dentro da parte do canto relativa ao gado de pequeno porte (vv. 286-473), ${ }^{2}$ o trecho em que o poeta-magister adverte sobre os perigos representados, para o gado, pelos ofídios venenosos

${ }^{2}$ O gado ovino e o caprino. Os vv. 49-285 são dedicados ao gado de grande porte (bovino e equino), de forma que o "miolo" do canto 3 apresenta essas duas grandes divisões de acordo com o porte dos animais. Podem-se reconhecer duas outras partes (vv. 1-48 e vv. 474-566), uma antes e outra depois daquelas duas divisões maiores. Do verso 1 ao 48, antes, portanto, de iniciar a abordagem propriamente dita da criação de animais, o poeta insere uma nova sequência invocação-proposição-dedicatória, agora exclusivas do livro 3 (já houvera uma, geral à obra, no início do canto 1): invoca divindades pastoris, adequadas ao assunto do livro (vv. 1-2), anuncia os temas que serão tratados (vv. 3-12) e faz novamente a dedicatória do canto a Mecenas (vv. 40-48), além de realizar uma minuciosa descrição de um templo que erigirá a César Augusto para celebrar a divindade triunfante do imperador (vv. 13-39). A outra parte, que seria a quarta divisão do livro 3 , compõe-se do trecho entre os versos 474 e 566, os quais descrevem a peste que teria acometido a região do Noricum e do leste da Gália Cisalpina, uma epizootia que teria provocado a morte de todo tipo de animal, chegando a atingir até mesmo seres humanos. $\mathrm{O}$ clima pesado e sombrio dessa parte final confere uma nota pessimista ao fecho do livro 3 .

Sobre as duas divisões segundo o porte do gado citadas acima, percebe-se, pelo confronto de duas importantes passagens propositivas das Geórgicas (1.1-5 e 3.286288), que o poeta aplica, ao menos nessas duas passagens e em algumas outras, o termo armentum para o gado "graúdo", e o termo pecus para o gado "miúdo". Entretanto, um exame detalhado de todos os usos, nas Geórgicas, dos dois termos não mostra sempre essa distinção, pois os encontramos utilizados indiferentemente com ambas as acepções (cf., por exemplo, pecori... equino, "gado equino", em 3.72), ou - o que é mais frequente - com seu sentido genérico de "gado", "rebanho", "reunião ou aglomeração de animais da mesma espécie", sem relação direta com um tamanho específico de animal (por exemplo, armenta em 1.355 e pecori em 1.444). 
(vv. 414-439). O trecho é curto (26 versos), mas permite muitas e instigantes considerações, não só pela beleza da passagem, rica em efeitos de som, sintaxe e ritmo, mas também pela relação autotextual ${ }^{3}$ que se estabelece entre alguns de seus versos e duas famosas passagens da Eneida: o episódio da morte do sacerdote Laocoonte e de seus filhos por duas serpentes saídas do mar (En., 2.199-227) e o início do trecho que narra a execução do rei Príamo por Pirro (En., 2.469-475).

Neste artigo, exploraremos, a partir do referido trecho das Geórgicas, esses dois aspectos (o dos efeitos de som, sintaxe, ritmo e o da autotextualidade), os quais, nunca é demais advertir, não são, de forma alguma, limitados ao trecho em questão, constituindo, ao contrário, características inseparáveis do estilo de Virgílio. Como um objetivo adicional, examinaremos ainda de que maneira esses dois aspectos foram contemplados na versão de um dos maiores tradutores de Virgílio para o nosso idioma, o maranhense Manuel Odorico Mendes (1799-1864), ${ }^{4}$ responsável pelo feito impressionante de traduzir poeticamente ao português toda a obra de Virgílio e toda a obra de Homero, para ficarmos apenas nos poetas clássicos. ${ }^{5}$

\footnotetext{
${ }^{3}$ Ver a definição do conceito no início do item 4 , à frente.

${ }^{4}$ Sua tradução das Geórgicas foi publicada em 1858, como parte do Virgilio Brazileiro ou traducção do poeta latino por Manuel Odorico Mendes (Paris, Typographia de W. Remquet), obra que reunia as traduções odoricanas dos três poemas de Virgílio: Bucólicas, Geórgicas e Eneida. A Eneida, porém, já tinha saído, individualmente, em 1854 (Eneida brazileira ou traducção poética da epopéa de Publio Virgilio Maro (Paris, Typographia de Rignoux), tendo o seu texto recebido correções e alterações para a edição de 1858, que passou a contar também com o texto latino estampado junto da tradução. ${ }^{5}$ Seu legado tradutório vem sendo estudado, recuperado e revalorizado no Brasil desde fins da década de 70, em movimento que ganhou um importante ator com a fundação, em 1998, do Grupo de Trabalho Odorico Mendes, idealizado e coordenado por Paulo Sérgio de Vasconcellos, professor de Língua e Literatura Latina da Universidade Estadual de Campinas (Unicamp). O Grupo, de que fazemos parte desde a sua fundação, conta com docentes de várias instituições de ensino superior brasileiras e já publicou, nas duas primeiras fases do projeto, as edições anotadas e comentadas das traduções de Odorico Mendes da Eneida (Editora da Unicamp, 2008, reimpressão em 2016) e das Bucólicas (Editora da Unicamp/Ateliê Editorial, 2008). Na atual terceira fase do projeto, o Grupo de Trabalho acaba de concluir a edição da tradução odoricana das Geórgicas, obra já no prelo e em avançado estágio no processo editorial.
} 
Antes de mais, vejamos, pois, o trecho das Geórgicas a que estamos nos referindo, seguido da belíssima versão que lhe foi dada pelo tradutor brasileiro, à qual apomos, para melhor compreensão, algumas poucas notas: 6

Disce et odoratam stabulis accendere cedrum, Galbaneoque agitare graves nidore chelydros.

Saepe sub immotis praesepibus aut mala tactu Vipera delituit, coelumque exterrita fugit; Aut tecto assuetus coluber succedere et umbrae, Pestis acerba boum, pecorique aspergere virus, Fovit humum. Cape saxa manu, cape robora, pastor; 420 Tollentemque minas et sibila colla tumentem Dejice: jamque fuga timidum caput abdidit alte, Cum medii nexus extremaeque agmina caudae Solvuntur, tardosque trahit sinus ultimus orbes. Est etiam ille malus Calabris in saltibus anguis,

Squamea convolvens sublato pectore terga, Atque notis longam maculosus grandibus alvum, Qui, dum amnes ulli rumpuntur fontibus, et dum Vere madent udo terrae ac pluvialibus austris, Stagna colit; ripisque habitans hic piscibus atram Improbus ingluviem, ranisque loquacibus explet. Postquam exhausta palus, terraeque ardore dehiscunt, Exsilit in siccum, et, flammantia lumina torquens, Saevit agris, asperque siti, atque exterritus aestu. Ne mihi tum molles sub divo carpere somnos, Neu dorso nemoris libeat jacuisse per herbas, Cum, positis novus exuviis, nitidusque juventa,

\footnotetext{
${ }^{6}$ Retiradas da edição, no prelo, citada na nota anterior. Trata-se de notas de nossa autoria, pois que, na referida edição, ficamos responsáveis por anotar e comentar a segunda metade do Canto 3.
} 
Volvitur, aut catulos tectis, aut ova relinquens, Arduus ad Solem, et linguis micat ore trisulcis!

(VIRGÍLIO, Geórgicas, 3.414-439) ${ }^{7}$

Perfume teus currais galbano ou cedro ${ }^{8}$

O olor graves quelidros afugenta. ${ }^{9}$

Em não mundos redis à luz se furta ${ }^{10}$

Víbora ao tato ingrata; ou lá no quente ${ }^{11}$

Peste acerba se aninha, a teto e sombra ${ }^{12}$

Cobra avezada, que envenena as reses: $:^{13}$

Silvando a inchar o colo e erguendo ameaças, ${ }^{14}$

Pedras e pau na mão, pastor, abate-a;

Já medrosa a cabeça em fuga embrenha, ${ }^{15}$

Nós do meio desata e anéis da cauda,

\footnotetext{
${ }^{7}$ Mantemos o texto latino tal qual estampado no Virgilio Brazileiro (e que estará também na edição comentada do Grupo Odorico Mendes); nele, usam-se as letras " $v$ " e "j" para representar as semivogais latinas "u" e "i".

${ }^{8}$ Galbano: planta (Ferula galbaniflua) da família das umbelíferas, de que se extrai a goma-resina de mesmo nome; ou, ainda, alguma outra planta do gênero Ferula, todas aromáticas e usadas na produção de resinas (a mais conhecida é a assa-fétida, segundo Mayer, 1948, p. 395). A forma paroxítona galbano, embora menos frequente que a proparoxítona, está registrada no Dicionário Aurélio. Cedro: aqui, provavelmente, a árvore conhecida como cade ou oxicedro (Juniperus oxycedrus), já que o poeta menciona suas propriedades odoríferas. Extrai-se do cerne dessa árvore, nativa do sul da Europa e do Cáucaso, um líquido negro e fétido, inflamável, chamado óleo de cade. Perfume teus currais galbano ou cedro: isto é, "galbano ou cedro perfume teus currais".

${ }^{9}$ Graves: perigosos, perniciosos; quelidros: cobras d'água.

${ }^{10}$ Mundo: limpo; redis: currais, estábulos; à luz se furta: foge, esconde-se da luz.

${ }^{11}$ Ao tato ingrata: desagradável, perigosa quando tocada.

${ }^{12}$ Acerba: atroz, terrível.

${ }_{13}$ Avezada: acostumada, afeita. A teto e sombra cobra avezada: "cobra avezada (acostumada) a teto e sombra".

${ }^{14}$ Silvando: sibilando, assobiando; erguendo ameaças: erguendo a cabeça de maneira ameaçadora.

${ }^{15}$ Embrenha: esconde-se em brenha, mato (MORAES, s.u.).
} 
Atrai o último seio espiras tardas. ${ }^{16}$

Feia serpente em Calabreses matas, ${ }^{17}$

Peito ereto, enovela o escâmeo tergo, ${ }^{18}$

Manchado ao longo o ventre: haja ribeira ${ }^{19}$

Que mane túrgida, ou nimbosos austros ${ }^{20}$

Ou mádido verão, nos charcos mora, ${ }^{21}$

$\mathrm{E}$ as margens discorrendo, o peixe engole, ${ }^{22}$

Mete em lôbrego papo as rãs palreiras; ${ }^{23}$

Se, esgotada a lagoa e a terra em fendas, ${ }^{24}$

Pula em seco, a torcer ignitos olhos ${ }^{25}$

Raiva de calma e sede exasperada. ${ }^{26}$

${ }^{16}$ Atrai: arrasta consigo; seio: curva, sinuosidade, dobra sinuosa; espiras: giros, voltas em espiral; tardas: vagarosas. O trecho dos vv. 406-408 pode ser assim explicado, segundo Conington \& Nettleship (1898, p. 324): a serpente, ferida, mete a cabeça num esconderijo (v. 406) e, à medida que vai arrastando o corpo para dentro, os anéis e voltas do corpo da serpente vão se desfazendo, se desatando (soluuntur), para permitir a entrada no refúgio, que é, evidentemente, estreito (v. 407). A última curva do corpo (sinus ultimus) do réptil traz consigo os últimos movimentos em espiral (orbis), já lentos (tardos) por causa, talvez, da situação já agonizante do animal (v. 408).

${ }^{17}$ Calabreses: calabresas (em português antigo, os adjetivos em -ês eram empregados também para qualificar substantivos femininos). A Calábria, na época de Augusto, era o território do "salto" da bota itálica, correspondendo hoje a uma parte da região da Puglia. Modernamente, dá-se o nome de Calábria ao "bico" da bota.

${ }^{18}$ Enovela: enrola em forma de novelo; escâmeo: cheio de escamas; tergo: dorso, costas.

${ }^{19}$ Ao longo: em toda a grande extensão (do ventre); haja: (caso) haja, quando há, enquanto há; ribeira: curso d'água menor que um rio.

${ }^{20}$ Mane: corra; túrgida: cheia; nimbosos: cheios de nuvens; austros: (plural poético) vento do sul, quente e tempestuoso.

${ }^{21}$ Mádido: úmido; verão: aqui, como no verso 272 e em outras passagens da tradução odoricana das Geórgicas (1.43; 2.149, 323; 4.22, 77 e 134), é sinônimo de "primavera", traduzindo o uer ("primavera") do original.

${ }^{22}$ Discorrendo: percorrendo.

${ }^{23}$ Lôbrego: sombrio, escuro; palreiras: tagarelas, loquazes.

${ }^{24} \mathrm{Se}$ : quando.

${ }^{25}$ Ignitos: feitos em brasa, chamejantes (MORAES, s.u.).

${ }^{26}$ Raiva: se enraivece; de: por; calma: calor intenso. Entenda-se: "raiva, exasperada de calma e sede". 
Nem ao sereno então pegue eu no sono,

Nem do mato na ourela me recline; ${ }^{27}$

Posto o espólio, eis se enrola e moça esplende, ${ }^{28}$

Ou na cova deixando ovos ou partos, ${ }^{29}$

Vibra direita ao Sol trifidas línguas. ${ }^{30}$

(Geórgicas, 3.398-423)

\section{2}

Notemos, primeiramente, que Virgílio emprega, na passagem, quatro diferentes vocábulos para designar o réptil: chelydrus (v. 415), ${ }^{31}$

${ }^{27}$ Ourela: beira, margem; do mato na ourela: na ourela do mato.

${ }^{28}$ Espólio: restos (acepção registrada pelo Dicionário Aurélio), ou seja, a pele velha trocada pela cobra; posto o espólio: tirada a pele velha; moça esplende: resplandece, remoçada (porque trocou de pele). Em ordem direta, assim ficariam os vv. 419-421: "Nem, então, eu pegue no sono ao sereno, nem me recline na ourela do mato; posto o espólio, eis se enrola e esplende, moça..."

${ }^{29}$ Partos: filhotes recém-nascidos (MORAES, s.u.). A interpretação de "ou [...] ovos ou partos" (aut catulos [...] aut oua) não é unívoca. Segundo alguns, a expressão refere-se ao desconhecimento à época do poeta sobre o tipo de reprodução da serpente calabresa mencionada (as serpentes podem ser ovovivíparas - os ovos eclodem dentro do corpo da mãe, que expele os filhotes já fora do ovo - ou ovíparas - os ovos são expelidos e eclodem fora do corpo materno). Assim é como entende o tradutor, como ele próprio apontará em nota à sua tradução. Outros comentadores, como Conington \& Nettleship (1898, p. 325), consideram que "ou ovos ou partos" refere-se a dois momentos diferentes no tempo, o dos ovos postos pela fêmea no ninho e o da eclosão efetiva dos mesmos, posteriormente. Tais comentadores estariam assumindo, portanto, que a serpente em questão é ovípara. Mas lembremos, tendendo à primeira interpretação, que ainda hoje os biólogos debatem sobre qual o modo de reprodução de certas espécies de serpentes, de forma que não é de se estranhar alguma insegurança dos antigos quanto a esse tema. ${ }^{30}$ Direita: em direção a; direita ao Sol: com a cabeça ereta na direção do sol; trifidas: divididas em três partes (a paroxítona, menos comum que a proparoxítona trífida, está registrada no Aurélio). Como a língua das serpentes não é tripartida, e sim bipartida, provavelmente o poeta não quis dizer, com o termo, que a língua da serpente é dividida em três partes, mas sim que ela vibra tão rapidamente que o animal parece ter três línguas. ${ }^{31}$ Já aparecera em $G$., 2.214, a outra única ocorrência do termo no poema. 
uipera (v. 417), coluber (v. 418) e anguis (v. 425). ${ }^{32}$ Não parece, contudo, que o poeta tenha se preocupado em usar os termos com precisão semântica, mesmo porque somente chelydrus é vocábulo mais específico, designando um tipo de serpente anfíbia. Vipera designa o ofídio venenoso de reprodução vivípara, como mostra sua possível etimologia (uipera < uiuus + pario: aquela que pare os filhotes vivos). Mas esse dado pouco ajuda, pois todos os animais mencionados na passagem referem-se a exemplares peçonhentos, dada a ênfase nos cuidados a serem tomados para se protegerem tanto o homem quanto o rebanho: a uipera é dita mala tactu, "ingrata ao toque"; a coluber, pestis acerba bouis, "peste cruel aos bois", assuetus pecori aspergere uirus, "acostumada a derramar o veneno no rebanho"; a anguis, malus, "malfazeja". Da mesma forma, coluber é termo genérico para os ofídios, bem como anguis, com a diferença de que este último é usado quase sempre em poesia, segundo Ernout \& Meillet (2001, p. 33).

De qualquer forma, nota-se que Odorico Mendes conservou a riqueza lexical do texto latino, escolhendo, igualmente, quatro vocábulos portugueses para verter chelydrus, uipera, coluber e anguis: "quelidro", "víbora", "cobra" e "serpente", respectivamente. Assim, mantém-se bem fiel ao original ao respeitar a maior especificidade de chelydrus (que ele traduz por "quelidro") e a maior generalidade de coluber, anguis (traduzidos por "cobra" e "serpente", termos sinônimos e generalizantes, em português, para os animais dessa subordem ${ }^{33}$ ) e uipera (traduzido por seu correspondente etimológico em português, "víbora", designação igualmente genérica para vários tipos de serpentes venenosas).

Entre os outros tradutores das Geórgicas para a nossa língua, nem todos se mostraram sensíveis a essa diversidade vocabular, conforme se pode ver na tabela a seguir:

\footnotetext{
${ }^{32}$ Ainda que aqui só nos interesse o trecho G., 3.414-439, registremos que um quinto termo fora usado em G., 2.215: serpens.

${ }^{33}$ A subordem Serpentes ou Ophidia.
} 


\begin{tabular}{|c|c|c|c|c|c|c|c|c|}
\hline $\begin{array}{c}\text { Virgílio, } \\
\text { Geórgicas }\end{array}$ & Verso & $\begin{array}{c}\text { Leonel } \\
\text { da Costa } \\
\text { Lusitano } \\
\mathbf{( 1 7 6 1 )}\end{array}$ & $\begin{array}{c}\text { Pina } \\
\text { Leitão } \\
\mathbf{( 1 7 9 4 )}\end{array}$ & $\begin{array}{c}\text { Odorico } \\
\text { Mendes } \\
\mathbf{( 1 8 5 8 )}\end{array}$ & $\begin{array}{c}\text { Antônio } \\
\text { Feliciano } \\
\text { de Castilho } \\
\mathbf{( 1 8 6 7 )} \\
{[\mathbf{1 9 5 2}]}\end{array}$ & $\begin{array}{c}\text { Ruy } \\
\text { Mayer } \\
\mathbf{( 1 9 4 8 )}\end{array}$ & $\begin{array}{c}\text { Agostinho } \\
\text { da Silva } \\
\text { (1997) }\end{array}$ & $\begin{array}{c}\text { Casemiro } \\
\text { Leopoldo } \\
\text { Chociay } \\
\text { (2019) }\end{array}$ \\
\hline chelydrus & 415 & quilidro & serpente & quelidro & quelidro & cobra & cobra & serpente \\
\hline uipera & 417 & bíbora & áspide & víbora & víbora & víbora & víbora & víbora \\
\hline coluber & 418 & cobra & cobra & cobra & cobra & cobra & cobra & cobra \\
\hline anguis & 425 & serpente & serpe & serpente & cobra & serpente & cobra & serpente \\
\hline
\end{tabular}

Observa-se que somente Costa Lusitano, Pina Leitão e Odorico Mendes empregaram quatro vocábulos diferentes para verter os quatro termos latinos (Odorico parece, aliás, seguir de perto as escolhas de Costa Lusitano). Castilho repetiu "cobra" (usou-o para verter coluber e anguis). Ruy Mayer, cuja tradução visa antes ao conteúdo que à forma do texto, como ele próprio admite em seu prefácio, ${ }^{34}$ também usou duas vezes "cobra", mas para verter chelydrus e coluber. Já Agostinho da Silva não se preocupou em manter a diversificação lexical, empregando apenas dois vocábulos, um dos quais (de novo, "cobra") repetido três vezes. Chociay, cuja versão, como a de Mayer, é feita em prosa, também adotou duas vezes um mesmo termo, no caso, "serpente" (para verter chelydrus e anguis). ${ }^{35}$

\footnotetext{
${ }^{34}$ MAYER, 1948, p. 10-11.

${ }^{35}$ Tomando-se não os tradutores individualmente, mas a comparação entre eles, podemse fazer outras observações interessantes a partir da tabela: 1) os sete tradutores vertem coluber por seu correspondente direto "cobra" (na verdade, "cobra" < colubra, mas este é cognato de coluber); 2) todos vertem uipera por seu descendente "víbora"/"bíbora", exceção feita a Pina Leitão; 3 ) só três tradutores optam por manter a maior especificidade de chelydrus ("quelidro"/“quilidro"); 4) além de "cobra", "serpente", víbora" e "quelidro", são usados somente mais dois termos: "áspide" e "serpe", este último, derivado da mesma palavra latina que "serpente" (serpens, serpentis), mas a partir do radical do nominativo.
} 
Esse mesmo tipo de diversificação lexical dentro de uma passagem (e, de novo, envolvendo a subordem dos Ofídios) será novamente adotada por Virgílio mais tarde, na Eneida, na narrativa da morte de Laocoonte e seus filhos (En., 2.199-227), quando empregará, para designar as duas serpentes marinhas que os atacam, primeiro o termo (no plural) angues (v. 204); depois, a expressão uterque serpens (v. 214); e, finalmente, dracones (v. 225), esta última pondo em destaque a aura mitológica amiúde relacionada ao réptil. Odorico Mendes, que, antes das Geórgicas, também tinha traduzido a Eneida ${ }^{36}$ empregara, na versão do poema épico, "serpes" para verter angues, e "dragões", bem literal, para verter dracones; já para uterque serpens não adotou um termo específico relativo ao grupo dos ofídios, optando pela perífrase "o par medonho". Buscou, de qualquer forma, manter a riqueza original do texto latino, como fará depois na tradução das Geórgicas. ${ }^{37}$

\section{3}

Passando agora ao exame de algumas características formais do texto virgiliano que produzem efeitos de leitura bastante interessantes, contribuindo enormemente para a poeticidade dos conteúdos expressos, devemos notar que vários versos do trecho das Geórgicas relativo aos cuidados que os pastores devem adotar para evitar que seus rebanhos sejam atacados por serpentes são fortemente marcados pela aliteração da consoante fricativa /s/, som que costuma ser associado, na tradição poética, ao silvo característico das cobras ou serpentes. A reiteração da sibilante /s/ mimetizaria, portanto, a "voz" das serpentes de que trata o trecho. O recurso é explorado por Virgílio, em maior ou menor grau, ao longo de toda a passagem em análise, mas vejamos alguns dos versos em que tal efeito é mais evidente e observemos a preocupação de Odorico em manter a figura sonora:

\footnotetext{
${ }^{36}$ Ver nota 4.

${ }^{37}$ Note-se que a cronologia de tradução, por Odorico, das obras de Virgílio se dá numa ordem quase oposta à cronologia em que este compôs seus poemas. Em outras palavras, Virgílio compõe Bucólicas, Geórgicas e Eneida, nesta ordem; Odorico traduziu primeiro a Eneida (1854), depois Bucólicas e Geórgicas (1858).
} 
Solvuntur, tardoSque trahit SinuS ultimuS orbeS. (v. 424).

Atrai o último Seio eSpiraS tardaS. (v. 408).

ESt etiam ille maluS CalabriS in SaltibuS anguiS,

Squamea convolvenS Sublato pectore terga, (vv. 425-426)

Feia Serpente em CalabreseS mataS,

Peito ereto, enovela o eScâmeo tergo, (vv. 409-410)

Cum, poSitiS novuS eXuviiS, nitiduSque juventa,

Volvitur, aut catuloS tectiS, aut ova relinquenS,

ArduuS ad Solem, et linguiS micat ore triSulciS! (vv. 437-439)

PoSto o eSpólio, eiS Se enrola e moÇa eSplende,

Ou na cova deixando ovoS ou partoS,

Vibra direita ao Sol trifidaS línguaS. (vv. 421-423)

Aqui, mais uma vez devemos lembrar que o expediente será de novo adotado por Virgílio na Eneida, pois que o episódio da morte de Laocoonte pelas serpentes monstruosas é todo ele repleto, igualmente, de sibilantes, algo que salta aos olhos (e aos ouvidos) em trechos como este:

Fit SonituS, Spumante Salo: jamque arva tenebant, ArdenteSque oculos Suffecti Sanguine et igni,

Sibila lambebant linguiS vibrantibuS ora.

DiffugimuS viSu eXSangueS. (En., 2.209-212)

Na tradução de Odorico, que mantém a aliteração:

Soa eSpumoso o páramo Salgado.

Já tomam a terra, e em braSa e cruor tintoS

Fulmineos olhoS, com vibradaS linguaS

Vinham lambendo aS SibilanteS bocaS.

Tudo eXangue Se eSpalha. (En., 2.210-214) $)^{38}$

\footnotetext{
${ }^{38}$ Texto latino e tradução odoricana retirados da edição da Eneida do Grupo Odorico Mendes (2008), edição essa que, como já informado, reproduz os textos do Virgilio Brazileiro (1858). A mesma observação vale para os outros trechos da Eneida citados neste artigo.
} 
Outro recurso empregado no trecho de Geórgicas, 3.414-439, agora com o fito provável de representar o corpo comprido e longilíneo das serpentes citadas, é o - digamos - "encompridamento" sintático e espacial de alguns versos, o que se dá pela opção de uso exclusivo (ou quase exclusivo) de pés dátilos (em vez de espondeus) em todas as posições do hexâmetro. Com isso, o verso se alonga, sintática, métrica e graficamente, uma vez que uma sílaba longa é substituída por duas breves, perfazendo, ao final da contagem, um número maior de sílabas no verso. Veja-se o caso do verso 437 na passagem abaixo, em que todos os pés são dátilos:

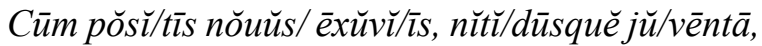

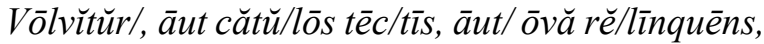

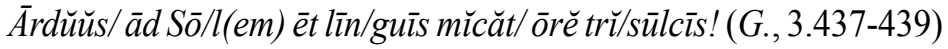

Para recriar esse efeito em sua tradução, Odorico lança mão da multiplicação das elisões:

Post(o) espóli(o), eis s(e) enrol(a) e moç(a) esplende, ${ }^{39}$

Ou na cova deixando ovos ou partos,

Vibra direita ao Sol trifidas línguas. (G., 3.421-423)

A mesma tática o tradutor adota no trecho das serpentes, mesmo quando o verso latino não traz o mencionado predomínio datílico, como se Odorico desejasse mesmo maximizar no texto em português o efeito existente só aqui e ali no original. Por exemplo, em

Est etiam ille malus Calabris in saltibus anguis,

Squāměă/ cōnvōl/uēns sū/blātō/pēctǒrěltēergă, (G., 3.425-426),

o verso 426 alterna espondeus e dátilos, mas o tradutor imprimiu à sua versão três elisões:

${ }^{39}$ Mas note-se também a elegante assonância da vogal /e/ contribuindo para a musicalidade do verso ("Posto o espólio, eis se enrola e moça esplende"), o que é ajudado pela repetição da sequência silábica e(i)s-: "Posto o espólio, eis se enrola e moça esplende"). A sonoridade desse verso talvez se deva ainda à alternância, ainda que não perfeita, entre vogais /e/ e /o/ fechadas e abertas: "Posto o espólio, eis se enróla e moça esplende" (marcamos as abertas com sinal agudo). 
Feia serpente em Calabreses matas, Peit(o) eret(o), enovel(a o) escâmeo tergo ${ }^{40}$ (G., 3.409-410)

\section{4}

Vejamos, agora, um interessante caso daquele fenômeno intertextual que Vasconcellos (2001, p. 148) chamou "autotextualidade" ou "autocitação", definindo-o como a "evocação, em dada obra, de uma passagem de outra obra do mesmo autor". ${ }^{41}$ No caso, trata-se de versos das Geórgicas que foram reaproveitados na Eneida. Referimo-nos ao trecho, há pouco analisado, de 3.437-439:

Cum, positis novus exuviis, nitidusque juventa,

Volvitur, aut catulos tectis, aut ova relinquens,

Arduus ad Solem, et linguis micat ore trisulcis! (G., 3.437-439)

Virgílio reutilizará dois desses versos (437 e 439) em En., 2.469475, na construção de um símile que descreve Pirro, filho do já falecido Aquiles, no momento em que ele inicia a invasão do palácio do rei Príamo, a quem irá executar cerca de cem versos depois. O símile compara o jovem Pirro, ufano, exultante e de armas reluzentes, com uma cobra que, após longa hibernação durante o inverno, desperta enfim, esplendorosa

\footnotetext{
${ }^{40}$ Note-se aqui, de novo, a assonância do /e/ ("Peito ereto, enovela o escâmeo tergo") e a alternância entre /e/ e /o/ abertos e fechados: "Peito eréto, enovéla o escâmeo térgo" (marcamos as abertas com sinal agudo). Mais um belo exemplo, no Canto 3 das Geórgicas, de uso de métrica e sintaxe expressivas para incremento da poeticidade está na passagem dos versos 470-473 (nesse caso, fora do trecho das serpentes): ao alertar para o perigo das epizootias, que invadem o rebanho com violência e rapidez maiores que as de um tufão, o poeta "encomprida" o verso 473 para representar a força da doença e o grande número de animais por ela atingidos; para tanto, usa pés dátilos ao longo de quase todo o hexâmetro e repete três vezes a enclítica -que: Spēmquĕ,

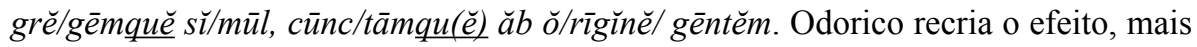
uma vez, multiplicando as elisões: "[corrompendo]/ a (e)speranç(a), e rebanh(o e) a raç(a) inteira").

${ }^{41}$ Em outro trabalho, o estudioso empregará, não sem se autocensurar pelo que considera "um monstrengo terminológico insuportável", o composto "auto-intertextualidade" (VASCONCELLOS, 2008, p. 17).
} 
com sua nova pele, que acabou de trocar, e sai, então, mais perigosa que nunca, deslizando o corpo e vibrando a língua trifurcada. Ressalta-se a juventude que caracteriza a ambos, a cobra e o cruel guerreiro, o qual, jovem e ambicioso por se igualar à glória e ao renome do pai, é sedento de sangue e mortandade:

Vestibulum ante ipsum primoque in limine Pyrrus

Exsultat, telis et luce coruscus ahena:

Qualis ubi in lucem coluber, mala gramina pastus,

Frigida sub terra tumidum quem bruma tegebat,

Nunc positis novus exuviis, nitidusque juventa,

Lubrica convolvit sublato pectore terga

Arduus ad Solem, et linguis micat ore trisulcis. (En., 2.469-475)

Odorico traduziu assim:

Pirro à entrada no pórtico ufaneia, ${ }^{42}$

Com o aço e lustre aêneo relumbrando: ${ }^{43}$

Tal, cevada em má grama, à luz a cobra, ${ }^{44}$

Que prenhe o brumal frio a soterrava, ${ }^{45}$

Nova a pele, se entesa, e moça e nédia ${ }^{46}$

Lúbrico o dorso enrola, árdua o Sol mira, ${ }^{47}$

Fulge e vibra a trissulca ardente língua. ${ }^{48}(E n ., 2.485-491)^{49}$

${ }^{42}$ Ufaneia: exulta, regozija-se.

${ }^{43}$ Aço: armadura; lustre aêneo: brilho do bronze (de suas armas); relumbrando: resplandecendo, brilhando.

${ }^{44}$ Cevada: alimentada, nutrida; má grama: ervas venenosas; à luz: ao sol.

${ }^{45}$ Prenhe: impregnada (de ervas venenosas); brumal frio: o frio do inverno.

${ }^{46}$ Nova a pele: sendo nova a pele, que acabou de trocar; se entesa (ao sol): se inteiriça, se estica; nédia: luzidia, lustrosa.

${ }^{47}$ Lúbrico: que desliza e se escapa com facilidade; árdua: elevando-se em direção ao sol, empinada.

${ }^{4}$ Trissulca: que possui três sulcos, em referência à impressão de que a língua das cobras era tripartida. Ver nota 30.

${ }^{49}$ As notas foram, em sua maioria, retiradas edição da Eneida do Grupo Odorico Mendes (2008). 
Os versos 437 e 439 do trecho das Geórgicas são praticamente idênticos aos versos 473 e 475 da Eneida (a única diferença é a substituição, nesta última, de cum por nunc no primeiro pé poético do v. 473). Mas a autotextualidade não para por aí. $\mathrm{O}$ verso 474 do poema épico também é emprestado das Geórgicas, mas de um trecho situado um pouco antes, no mesmo canto. Observe-se:

Est etiam ille malus Calabris in saltibus anguis,

Squamea convolvens sublato pectore terga, (G., 3.425-426)

Feia serpente em Calabreses matas,

Peito ereto, enovela o escâmeo tergo, $(G ., 3.409-410)$

Lubrica convolvit sublato pectore terga $(E n ., 2.474)$

Lúbrico o dorso enrola, [...] (En., 2.490) $)^{50}$

Como se percebe, o verso 426 das Geórgicas é reutilizado, quase que integralmente, na Eneida, apenas com a substituição de squamea por lubrica e com a mudança na morfologia verbal do verbo conuoluere. ${ }^{51}$

Em suma, En. 2.473-475 é uma combinação de G., 3.437 e 439 com $G$. 3.426. Mas que efeitos de sentido podem ser gerados na leitura do trecho da Eneida se o leitor detecta todas essas referências feitas aos passos das Geórgicas?

Parece-nos lícito pensar que o efeito de leitura é a dinamização ou maximização do símile da Eneida; em outras palavras, se a comparação de Pirro com uma cobra radiante e lustrosa com sua nova pele e sedenta por presas já se encontra no poema épico, a percepção de que são reaproveitados versos das Geórgicas que tratam dos riscos dos ofídios venenosos para o gado ressalta o perigo que o sanguinário Pirro representa para os inimigos troianos. Assim como as cobras do trecho 3.414-439 das Geórgicas precisam ser repelidas, evitadas, eliminadas, pois que

\footnotetext{
${ }^{50}$ Aqui, diferentemente da tradução das Geórgicas, Odorico não incluiu sublato pectore em sua versão.

${ }^{51}$ Note-se, porém, que o radical de convolvit (En., 2.474) também está presente no volvitur de G., 3.438.
} 
ameaçadoras, traiçoeiras, raivosas e famintas, uma verdadeira peste para os rebanhos, assim também o jovem guerreiro grego Pirro, exultante, feroz, atrevido e implacável, sedento por sangue e glória, representa um perigo para o rebanho de troianos, aos quais, aliás, vai trucidando sem dificuldades, na sequência da passagem, como se fossem um dócil rebanho de gado.

Uma vez detectada a autoalusão, o autotexto, é lícito também, se deslocarmos a interpretação para a figura do leitor mais do que para a do autor, examinar de que forma o trecho da Eneida afeta a interpretação da passagem das Geórgicas. Sabe-se que, em processos intertextuais, os dois textos podem se afetar mutuamente: a leitura do texto que contém a referência também pode interferir na do texto referido. ${ }^{52}$ Assim, se após lermos a passagem acerca de Pirro, na Eneida, voltarmos ao passo das Geórgicas, passaremos a notar, neste último, uma dimensão épica na luta dos pastores contra as serpentes que atacam o gado. Dizendo de outra forma, se na Eneida, Pirro - e, por extensão, o exército de invasores gregos - representam as serpentes, e o povo troiano ali representa o gado, nas Geórgicas, da mesma forma, os pastores representariam os heróis troianos principais (lembre-se de que Virgílio, no poema didático, se dirige sobretudo aos lavradores itálicos, romanos, descendentes míticos do povo troiano), os quais devem combater o inimigo ofídico que invade os currais (= os gregos que invadem Troia), a fim de salvar o povo da cidade, os troianos (= gado) do perigo representado pelo invasor peçonhento. A leitura exposta neste parágrafo explora, como se disse, a possibilidade de também se examinarem os efeitos de sentido gerados no texto aludido pelo texto que faz a alusão, em vez de se ficar limitado à lógica cronológica que admite a geração de tais efeitos apenas pelo texto aludido sobre o texto que faz a alusão. Em suma, a leitura do texto "imitador" influencia também a leitura do texto "imitado", se se situa o ponto de interpretação na recepção mais do que na produção.

\footnotetext{
${ }^{52}$ Ver Conte (1981, p. 150, apud Fedeli, 1989, p. 393-394); Fedeli (1989, p. 393-397); Fowler (2000, p. 129-130); Barchiesi (2001, p. 142); Hinds (1998, p. 52-83); Cesila (2008, p. 43-45 e p. 213-218).
} 
Notemos, por fim, que, a despeito de os versos de En. 2.473475 serem quase idênticos a $G$., 3.426, 437 e 439, Odorico Mendes não traduziu as duas passagens da mesma maneira. Isso, contudo, é uma opção consciente do tradutor, pois ele próprio declara, mais de uma vez, a sua preferência por esse tipo de variação. Vejamos.

Tratando dos versos repetidos dentro da Eneida (nesse caso, não exatamente casos de "autotextualidade", mas, como classifica Vasconcellos, "intratextualidade" 53 ou intra-intertextualidade" ${ }^{54}$ ), Odorico, nas suas notas aos versos latinos 655-691 (653-689 de sua tradução), afirma, acerca do verso 691 do Canto 7 (At Messapus equum domitor, Neptunia proles): 55 "O verso 691, por vezes repetido, ora o traduzo ao pé da letra, ora digo só o picador Messapo ou o Netúnio Messapo ou o Cavaleiro Messapo; crendo que, uma vez traduzido rigorosamente, não era preciso que sempre o fosse". ${ }^{56}$

Além disso, na primeira edição da Eneida (de 1854), em nota aos versos 892-901 (vv. 931-939 da tradução), Odorico Mendes escrevera, ao tratar de En. 6.902 (Anchora de prora jacitur; stant littore puppes), que repete En., 3.277: "Todos os versos repetidos na Eneida, eu os traduzo diferentemente, conservando contudo o sentido, e só variando nas palavras". ${ }^{57}$

Tais declarações podem ser estendidas, acreditamos, para os versos das Geórgicas reempregados na Eneida, mostrando que o tradutor maranhense também nesses casos optou, conscientemente, por variar a expressão ao traduzir versos que eram idênticos ou muito semelhantes no original latino. Se isso pode dificultar, ao leitor das duas traduções, a percepção do autotexto, deve-se lembrar, porém, "que o estudo

\footnotetext{
53 “[...] a evocação, no curso de uma obra, de passagens da mesma obra: alusão interna, portanto" (VASCONCELLOS, 2001, p. 130).

${ }^{54}$ Vasconcellos (2008, p. 17).

${ }^{55}$ Repetido, por vezes com pequenas alterações, em 9.523, 10.353-354, 12.128 e 12.550. ${ }_{56}$ As observações desse parágrafo e do seguinte se baseiam nos apontamentos de Vasconcellos (2008, p. 16-17).

${ }^{57} \mathrm{Na}$ segunda edição, de 1858 (Virgilio Brazileiro), o tradutor suprimiria da nota, curiosamente, a frase aqui transcrita, como notou Vasconcellos (2008, p. 17, n. 27).
} 
mais sistemático da feição intertextual da poesia antiga é recente, e seria absurdo exigir de Odorico respeito a um dado do texto que ele provavelmente deveria analisar de maneira muito diferente da nossa" (VASCONCELLOS, 2008, p. 17). Cabe aos analistas de hoje, mais familiarizados com os modelos de análise intertextual em voga nas letras clássicas a partir de meados do século XX, explorar mais profundamente os efeitos de sentido derivados de tais processos intertextuais (ou autotextuais) envolvendo Geórgicas e Eneida.

\section{Referências}

AURÉLIO, A. B. H. F. Novo dicionário da língua portuguesa. Rio de Janeiro: Nova Fronteira, 1995.

BARCHIESI, A. Some Points on a Map of Shipwrecks. In:

Speaking Volumes. Narrative and intertext in Ovid and other Latin Poets. Londres: Duckworth, 2001. p. 141-154. Tradução inglesa do original italiano: Otto punti su una mappa dei naufragi.

CESILA, R. T. O palimpsesto epigramático de Marcial: intertextualidade e geração de sentidos na obra do poeta de Bílbilis. 2008. 298f. Tese (Doutorado em Linguística) - Instituto de Estudos da Linguagem, Unicamp, Campinas, 2008.

CONINGTON, J.; NETTLESHIP, A. The Works of Virgil. With a commentary by John Conington and Henry Nettleship. Londres: George Bell and Sons, 1898.

ERNOUT, A.; MEILLET, A. Dictionnaire étymologique de la langue latine. Histoire des mots. Paris: Klincksieck, 2001.

FEDELI, P. Le intersezioni dei generi e dei modelli. In: G. CAVALLO; P. FEDELI; A. GIARDINA (org.). Lo Spazio letterario di Roma Antica. Roma: Salerno, 1989. p. 375-397. v. 1.

FOWLER, D. Roman Constructions: Readings in Postmodern Latin. Oxford, New York: Oxford University Press, 2000.

HINDS, S. Allusion and Intertext: Dynamics of Appropriation in Roman Poetry. Cambridge: Cambridge University Press, 1998. 
MAYER, R. Geórgicas de Vergílio: versão em prosa dos três primeiros livros e comentários de um agrônomo. Lisboa: Sá da Costa, 1948.

MENDES, M. O. Bucólicas. Tradução e notas de Odorico Mendes. Edição anotada e comentada pelo Grupo de Trabalho Odorico Mendes. Cotia: Ateliê Editorial; Campinas: Editora da Unicamp, 2008.

MENDES, M. O. Eneida Brasileira. Tradução poética da epopéia de Públio Virgílio Maro. Organização de Paulo Sérgio de Vasconcellos et alii. Campinas: Editora da Unicamp, 2008.

MENDES, M. O. Eneida Brazileira ou traducção poetica da epopea de Publio Virgilio Maro. Paris: Typographia de Rignoux, 1854.

MENDES, M. O. Geórgicas de Virgílio. Tradução de Odorico Mendes. Organização de Paulo Sérgio de Vasconcellos et alii. Edição anotada e comentada pelo Grupo de Trabalho Odorico Mendes. Campinas: Editora da Unicamp; Cotia: Ateliê Editorial, 2019. No prelo.

MENDES, M. O. Virgilio Brazileiro ou traducção do poeta latino por Manuel Odorico Mendes. Paris: Typographia de W. Remquet, 1858.

MORAES, A. de M. Silva. Diccionario de lingua portuguesa. Rio de Janeiro: Officina da S. A. Litho/Typographia Fluminense, 1922.

VASCONCELLOS, P. S. de. Efeitos Intertextuais na Eneida de Virgílio. São Paulo: Humanitas, 2001.

VASCONCELLOS, P. S. de. Introdução à Eneida de Odorico Mendes. In: M. O. MENDES. Eneida Brasileira. Tradução poética da epopéia de Públio Virgílio Maro. Organização: Paulo Sérgio de Vasconcellos et alii. Campinas: Editora da Unicamp, 2008. p. 9-18.

VIRGÍLIO. As Eclogas e Georgicas de Vergilio. Tradução de Leonel da Costa Lusitano. Lisboa: Oficina de Miguel Manescal da Costa, 1761.

VIRGÍLIO. Geórgicas. Poema Didático. Tradução, comentário e notas elucidativas de Casemiro Leopoldo Chociay. São Paulo: PerSe, 2019.

VIRGÍLIO. Geórgicas. Tradução de Antonio Feliciano de Castilho. Rio de Janeiro: Jackson, 1952. 
VIRGÍLIO. Obras de Virgílio. Tradução de Agostinho da Silva. Lisboa: Temas e Debates, 1997.

VIRGÍLIO. Traducção livre ou imitação das Georgicas de Virgilio em verso solto, e outras mais composições poeticas. Tradução de Antonio José Ozorio de Pina Leitão. Lisboa: Typografia Nunesiana, 1794.

Recebido em: 5 de novembro de 2019. Aprovado em: 27 de novembro de 2019. 